$\begin{array}{lll}\text { Submission: 22/Feb/2017; } & 1^{\text {st }} \text { round notif.: 22/May/2017; } & \text { New version: 17/Oct/2017; } \\ \text { Camera ready: 23/May/2018; } & \text { Edition review: 01/Sep/2018; } & \text { Available online: 01/Sep/2018; } \quad \text { round notif.: 24/Nov/2017 }\end{array}$

\title{
Contribuição e avaliação de uma ferramenta de apoio ao ensino de otimização linear
}

\section{Title: Contribution and evaluation of a support tool for linear optimization teaching}

$\begin{array}{ll}\text { Elke Dias de Sousa } & \text { Karly Barbosa } \\ \text { Universidade } & \text { Alvarenga } \\ \text { Estadual de Goiás } & \text { Universidade } \\ \text { sousaelke@gmail.c } & \text { Federal de Goiás } \\ \underline{\text { om }} & \underline{\text { karlyba@yahoo.com }} \\ & \underline{. b r}\end{array}$

\author{
José Elmo de \\ Menezes \\ Pontificia \\ Universidade \\ Católica de Goiás \\ jelmo.maf@gmail.c \\ $\underline{o m}$
}

\author{
Marco Antonio \\ Figueiredo Menezes \\ Pontifícia \\ Universidade \\ Católica de Goiás \\ marco@pucgoias.edu \\ .$b r$
}

\author{
Duelci Aparecido \\ de Freitas Vaz. \\ Pontificia \\ Universidade \\ Católica de Goiás \\ duelci.vaz@gmail.c \\ om
}

\begin{abstract}
Resumo
Neste trabalho, são examinadas as contribuições da Calculadora LOpt ao ser inserida como uma ferramenta de apoio ao processo de ensino e aprendizagem da disciplina de pesquisa operacional. O estudo envolveu um professor coordenador, uma aluna desenvolvedora, dois professores que aplicaram o questionário para alunos de cursos distintos de duas instituições privadas de ensino superior no estado de Goiás no Brasil. Desenvolveu-se um questionário, o qual foi aplicado em duas turmas de graduação constituídas de 81 participantes. As análises e interpretações dos dados geraram evidencias de que o uso do software na resolução de problemas de otimização linear por meio do método simplex contribui significativamente no processo de ensino e aprendizagem desta disciplina, pois facilita a resolução de problemas e cria um ambiente de aprendizagem interativo.
\end{abstract}

Palavras-chave: apoio ao ensino; otimização linear; educação mediada.

\begin{abstract}
In this paper we examine the contributions of the "Calculadora para Otimização Linear" (Calculadora LOpt) to be inserted as a tool to support the teaching and learning process of the operational research discipline. The study involved a coordinating teacher, a student, two teachers who applied the questionnaire to students from different courses of two private higher education institutions in the state of Goiás in Brazil. A questionnaire was developed, which was applied in two graduation groups constituted of 81 participants. The analysis and interpretations of the data generated evidence that the use of software in solving linear optimization problems through the simplex method contributes significantly to the teaching and learning process of this discipline, since it facilitates problem solving and creates an interactive learning environment.
\end{abstract}

Keywords: support for teaching; linear optimization; technology-mediated.

Cite as: Sousa, E. D. de., Alvarenga, K. B., Menezes, J. E., Menezes, M. A. F \& Vaz, D. A. de F. (2018). Contribution and evaluation of a support tool for linear optimization teaching (Contribuição e avaliação de uma ferramenta de apoio ao ensino de otimização linear). Brazilian Journal of Computers in Education (Revista Brasileira de Informática na Educação - RBIE), 26(3), 20-41. DOI: 10.5753/RBIE.2018.26.03.20 


\section{Introdução}

Devido ao grande número de setores em que a otimização linear se aplica (como na agricultura, na economia, na educação, nas indústrias, na pecuária, nos transportes, na saúde), se torna indispensável o estudo de alternativas metodológicas para o ensino desta disciplina para diversos cursos oferecidos em instituições de ensino superior. O primeiro método efetivo para resolver o problema de otimização linear contínua (programação linear - PL) e, ainda hoje, bastante utilizado, foi o método simplex, desenvolvido por Dantzig (1951).

$\mathrm{Na}$ incorporação de laboratórios com computadores para determinadas disciplinas, na instalação da internet para pesquisas em geral, na requisição de software em geral ou específico como uma ferramenta de apoio para professores e alunos, vemos a necessidade e a importância da tecnologia informática. Griffith (1998) observa que a tecnologia auxilia os alunos a desenvolverem um entendimento conceitual e habilidades para resolver problemas. Posada, Buchdid e Baranauskas (2016) afirmam que o número de pesquisas em informática na educação no Brasil vem aumentando significativamente, principalmente no período entre 2010-2014. Nesse sentido, para citar alguns trabalhos com o uso de tecnologias, Tan (2012) mostrou que o uso de calculadoras gráficas (uma ferramenta portátil e multifuncional) beneficia estudantes de alto, médio e fraco aproveitamento de matemática, considerando 65 estudantes préuniversitários de uma instituição privada de ensino superior, na Malásia, no estudo de probabilidades. Mateo, Borrell, Pla e Solsona (2017) propõem um protótipo de um novo software como um serviço para trazer benefícios da otimização linear para a atividade diária de pequenas empresas e pessoas comuns. Segundo os autores, a maior contribuição do trabalho deles é o desenho e a implementação de um serviço que combina o potencial de alguns dos mais populares resolvedores (solvers) de código aberto, tais como, lpsolve, glpk, cbc, symphony, dentre outros.

O uso de linguagens de programação, às vezes com excelente saída gráfica, exige do estudante um pré-requisito de programação e do entendimento da linguagem. Softwares que resolvem problemas de otimização linear exigem, para o seu entendimento funcional, um manual, inclusive para a entrada de dados. Além disso, não desenvolvem a aprendizagem do método.

Lazaridis, Paparrizos, Samaras e Sifaleras (2007) propõem o software web didático Visual LinProg para resolver problemas de PL, o qual se utiliza de técnicas de animação e visualização. O software foi avaliado em uma turma pequena de uma disciplina, em que os alunos responderam a um questionário. $\mathrm{O}$ resultado demonstrou que, em geral, os alunos ficaram satisfeitos com a ferramenta. Kydd (2012) apresenta um applet em Java-script que foi usado por professores e alunos para ilustrar graficamente conceitos fundamentais de PL e avalia os resultados em grupos de controle, com vantagem para aqueles que utilizaram o applet. Alencar, Rocha, Nogueira, Fernandes e Nunes (2012) desenvolvem um software educacional para o ensino do método simplex, denominado Rhodes 2.0, através de visualização gráfica 2D/3D e aplicam um questionário concluindo que o software pode ser uma ferramenta auxiliar útil no processo de ensino e aprendizagem de PL. Na literatura brasileira, também podemos encontrar alguns trabalhos com a mesma ideia do SPLINT (Simplex INTerativo); Pinto e Bornstein (2006) elaboraram uma implementação interativa do algoritmo simplex tabular fases 1 e 2 para PL. Mais recentemente, Zamora e Torres (2017) propõem o uso de uma aplicação chamada POWTOON (disponível gratuitamente na internet) como uma estratégia de ensino e aprendizagem para criar vídeos e apresentações a fim de aprender tópicos específicos de pesquisa operacional.

Além da parte gráfica, a parte algébrica é fundamental no estudo da pesquisa 
operacional. No entanto, as dificuldades de alunos em realizar cálculos básicos, como, por exemplo, a resolução de sistemas e operações com matrizes, tão presentes nos métodos estudados em disciplinas da pesquisa operacional, têm sido um grande complicador para os professores que ministram tais disciplinas. Por outro lado, o importante no aprendizado de métodos como o Simplex, por exemplo, são as tomadas de decisão em cada passo da resolução dos problemas. Além disso, o tempo gasto com estes cálculos básicos é elevado e tira o foco do método, por parte dos estudantes. Em sala de aula, problemas clássicos e relevantes no estudo do Simplex, como os exemplos de Beale (1955), Klee e Minty (1072), dificilmente são abordados pelo professor, devido ao tempo. A partir daí, foi desenvolvido, em Fonseca e Pinto (2013), um sistema web didático de apoio para professores e estudantes de cursos com disciplinas de PL, denominado Calculadora para Otimização Linear (Calculadora LOpt). O sistema oferece todas as operações necessárias para a resolução rápida e passo a passo de problemas de PL por meio do algoritmo Simplex. Em particular, o diferencial da Calculadora LOpt é que o estudante mantém o foco na tomada de decisão do método, enquanto a execução das contas secundárias são feitas pelo software; as quais não necessariamente são importantes para o aprendizado do método.

Este estudo foi, portanto, realizado para examinar as contribuições da Calculadora LOpt ao ser inserida como uma ferramenta de apoio ao processo de ensino e aprendizagem da disciplina de pesquisa operacional. Para isto, foi desenvolvido um instrumento de avaliação. O objeto de estudo é a análise das contribuições do software para a resolução de problemas de PL por meio do algoritmo Simplex para alunos da disciplina de pesquisa operacional. O objetivo é avaliar as contribuições que o software pode oferecer para a aprendizagem de alunos. Até o presente momento, não conhecemos nenhum outro trabalho da natureza da Calculadora LOpt.

Este trabalho se divide da seguinte forma: na seção 2, apresentamos a PL e o software; na seção 3, é feita a descrição do método bootstrap e o teste de hipótese adotados para a utilização do software no processo de ensino e aprendizagem, que delinearam e tornaram o trabalho de coleta e análise de dados viáveis; na seção 4, apresentamos e analisamos os resultados, incluindo ameaças à validade; e, na seção 5, apresentamos nossas considerações finais.

\section{Sobre PL e o software}

Inicialmente, introduziremos brevemente a PL e o método Simplex (veja, por exemplo, Alves \& Menezes, 2010).

\subsection{Programação linear}

Consideremos os números inteiros positivos $m$ e $n$. Dada uma matriz numérica $A, m \times n$ com coeficientes reais e vetores $b \in R^{m}$ e $c \in R^{n}$, o problema de PL no formato padrão é o problema de otimização:

$$
\begin{aligned}
& \text { (P) minimizar } c^{T} x \\
& \text { sujeito } a \text { : } A x=b \\
& \qquad x \geq 0 .
\end{aligned}
$$

O conjunto viável de $(P)$ é caracterizado como um poliedro com um número finito de pontos extremos e com pelo menos um ponto extremo quando não vazio. $O$ teorema fundamental da PL afirma que se $(P)$ admite solução ótima, então uma solução ótima é atingida em ao menos um ponto extremo (ou equivalentemente, solução básica viável) do conjunto 
viável.

Existem várias famílias de métodos para resolver um problema de PL, como algoritmos fortemente polinomiais, Simplex, Elipsóides, Afim-escala, Pontos interiores, Ponto-interiorinviável. O método mais utilizado, na prática, continua sendo o Simplex; com exceção de problemas de grande porte (veja, por exemplo, Gondzio \& Grothey, 2006).

A ideia do método Simplex consiste em caminhar pela fronteira do poliedro de um problema de PL, por meio de pontos extremos adjacentes com valores da função objetivo menores do que os valores anteriores. Enunciamos, a seguir, um algoritmo denominado algoritmo mestre na tentativa de exprimir, sob essa forma, as ideias do método Simplex.

Algoritmo 2.1: Mestre.

DADOS: $x^{0}$ solução básica viável inicial associada a uma matriz base inicial $B_{0}$.

$k:=0$.

\section{REPITA}

Escolha, se possível, uma nova variável básica

daquelas variáveis não básicas.

Escolha, se possível, uma nova variável não

básica daquelas variáveis básicas.

Atualize $B_{k+1}$ e $x^{k+1}$.

$k:=k+1$.

ATÉ QUE ‘convirja’.

Algoritmos Simplex se definem a partir das escolhas no algoritmo mestre. A primeira escolha pergunta se a partir de uma solução básica viável, em uma iteração $k$ do algoritmo, pode-se melhorar o valor da função objetivo. Se não for possível, obtém-se uma solução ótima. A segunda escolha pergunta se existe ponto extremo adjacente no poliedro, que define o conjunto viável e que melhora o valor da função objetivo. Se não for possível, certifica-se problema ilimitado. Atualiza-se a nova solução básica viável a partir de uma única troca de quem entra e de quem sai da matriz base, em cada iteração. O algoritmo 2.1 converge através de técnicas anti-ciclagem, por exemplo, a regra do menor índice quando das escolhas de quem entra e de quem sai da base.

A seguir, abordaremos sobre o software; conforme Fonseca e Pinto (2013).

\subsection{Software}

A Calculadora LOpt é um sistema web didático para o estudo dos algoritmos Simplex primal, dual e de pós-otimização. Ela realiza os cálculos de obtenção de inversas e multiplicações matriciais. O sistema considera dois tipos de usuários: o professor, que além de resolver problemas, também pode cadastrá-los; e o aluno, o qual está limitado à resolução de problemas. Figura 1.

O problema a ser resolvido é definido pelo usuário nessa tela, conforme demonstra a 


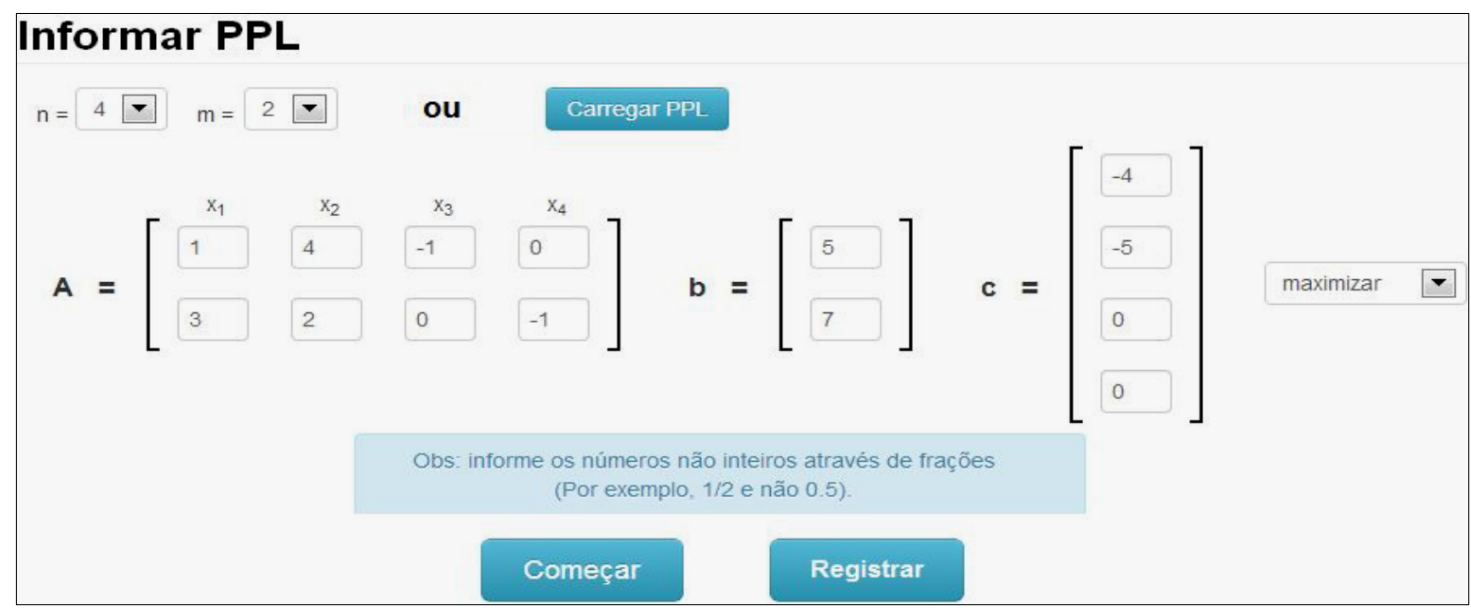

Figura 1: Tela para informar o PPL. Fonte: Fonseca e Pinto (2013).

O usuário pode informar o problema de PL de duas formas. Uma delas consiste em informar o número de variáveis (valores para $n$ ) e o número de restrições de igualdade (valores para $m$ ) e, assim, os dados do problema poderão ser digitados. A outra forma é clicando no botão Carregar PPL, para o qual será exibida uma lista de problemas já cadastrados no sistema, pois nesta tela o professor tem a possibilidade de cadastrar problemas. Basta que ele clique no botão Registrar que uma nova janela é exibida para que ele informe o enunciado, que deve dizer como o problema de PL deve ser resolvido e o método esperado para a resolução. Esse botão aparece apenas para o usuário do tipo professor. Uma vez que o professor cadastre a questão, ela fica no banco de problemas do sistema para que, posteriormente, todos os usuários possam acessá-la, resolvê-la e submeter a resolução para ser corrigida pelo sistema.

A interação com a Calculadora LOpt possibilita avaliar o aluno em relação ao conhecimento prévio dentro do conhecimento proposto e permite ao professor explorar problemas complexos, facilitando, assim, o seu trabalho de acompanhamento e correção das atividades, uma vez que esta acontece automaticamente. A Calculadora LOpt disponibiliza botões para realizar as operações necessárias, tanto para o Simplex primal quanto para o Simplex dual. Desta forma, o usuário deve clicar no botão desejado para realizar o cálculo e, com isto, reduz o tempo gasto com as contas em uma resolução tradicional.

Ao informar a primeira base através do conjunto de índices base do problema de PL, isto é, o conjunto de índices aos quais se referem as colunas da matriz tecnológica dada, $m \times n$, que definem a matriz base, denotado por $I_{B}$, todos os botões para se aplicar os algoritmos Simplex primal e Simplex dual são disponibilizados na calculadora LOpt, conforme ilustrado na Figura 2. Nessa tela, todos os cálculos são realizados e o usuário tem a permissão para alterar os dados do problema que está resolvendo. Contudo, se ele estiver resolvendo alguma questão cadastrada no sistema, as alterações podem desativar a correção automática. Além de tudo, qualquer conta pode ser feita sem seguir os passos de qualquer algoritmo, tornando possível, por exemplo, uma busca exaustiva para a resolução de problemas. 


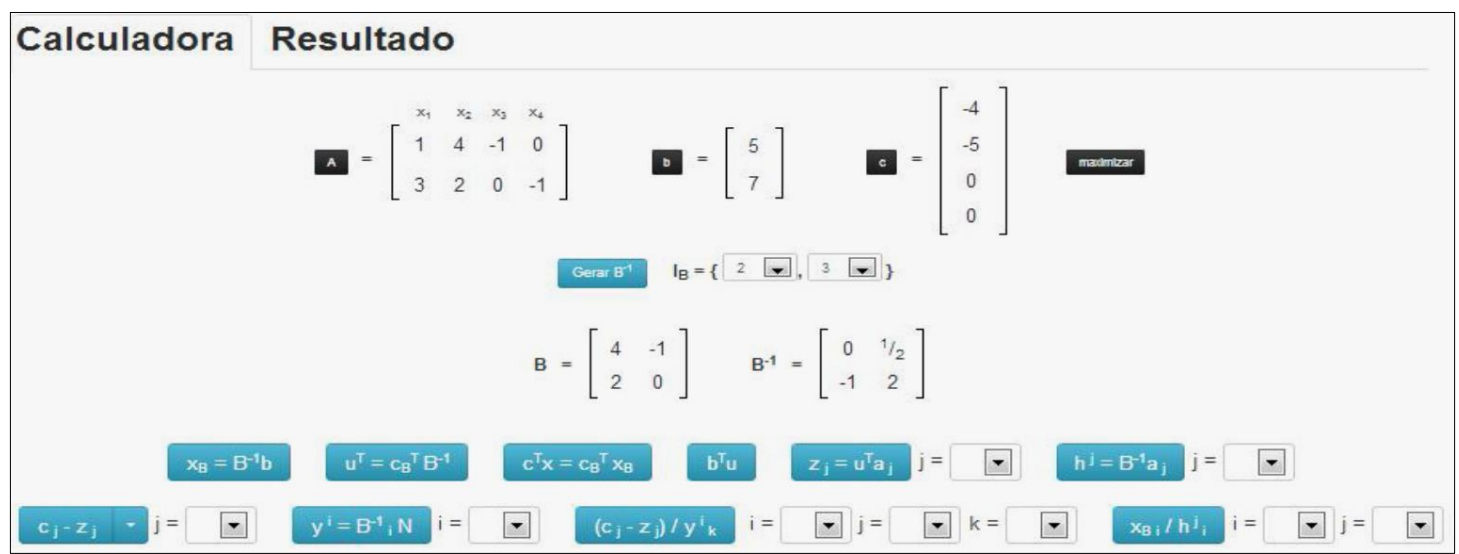

Figura 2: Tela para a realização dos cálculos. Fonte: Fonseca e Pinto (2013).

$\mathrm{Na}$ tela Resultado, apresentada na Figura 3, são mostrados todos os problemas considerados na resolução, juntamente com os problemas duais correspondentes. Nessa tela, o usuário tem a oportunidade de justificar, individualmente, cada operação realizada, ou apagar qualquer uma delas.

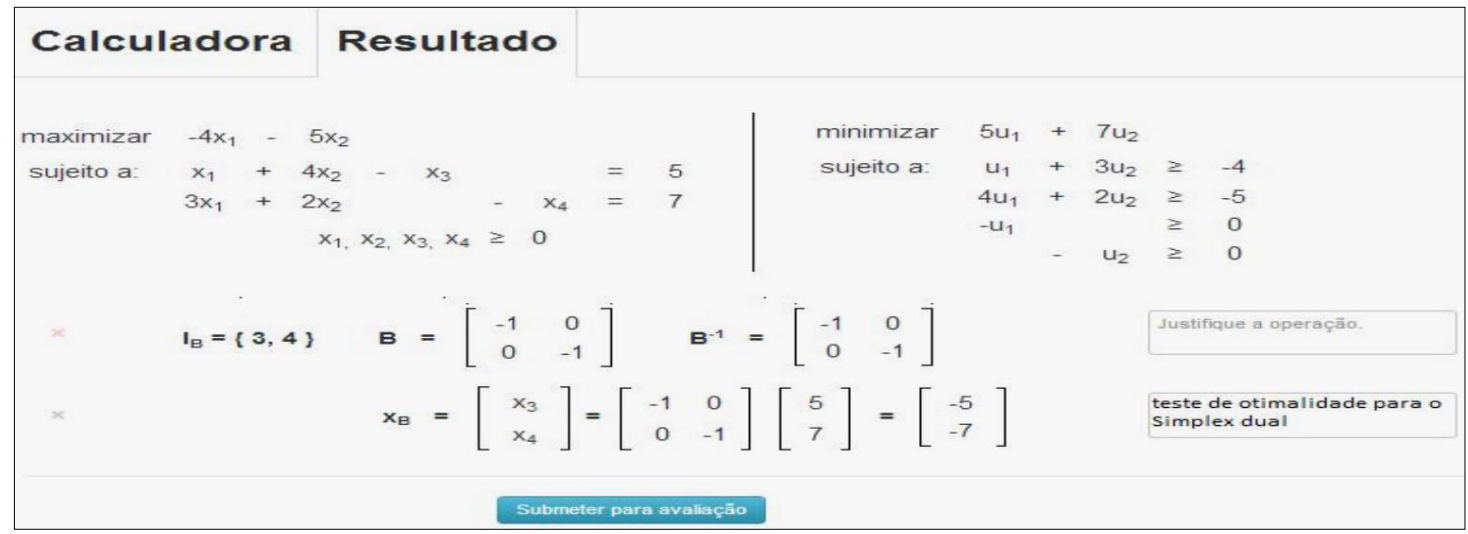

Figura 3: Tela de resultados e submissão para correção. Fonte: Fonseca e Pinto (2013).

Caso o usuário esteja resolvendo alguma questão cadastrada no banco de problemas, o botão Submeter será exibido na parte inferior da tela Resultado, como mostra a Figura 3. Após o usuário clicar nesse botão, o sistema faz a correção com base no método informado pelo professor no momento em que ele fez o cadastro do problema. Após a submissão de uma resolução, o sistema apresenta algumas mensagens para os usuários, contribuindo com o aprendizado do aluno. Assim, o aluno pode entender os motivos que o levaram ao erro. A Tabela 1 traz exemplos de mensagens dessa natureza.

Tabela 1: Mensagens da correção de questões.

\begin{tabular}{|c|}
\hline Mensagens da correção de qu \\
\hline $\begin{array}{l}\text { Parabéns, a sua resolução para esta questão } \\
\text { está correta. }\end{array}$ \\
\hline $\begin{array}{l}\text { Mais de um índice foi trocado do k-ésimo para } \\
\circ(k+1) \text {-ésimo } I_{B} \text {. }\end{array}$ \\
\hline $\begin{array}{l}\text { Nenhuma operação foi feita para a base do k- } \\
\text { ésimo } I_{B} \text {. }\end{array}$ \\
\hline $\begin{array}{l}\text { As operações realizadas não justificam ir do } \\
\text { k-ésimo para o }(k+1) \text {-ésimo } I_{B} .\end{array}$ \\
\hline $\begin{array}{l}\text { A sua última operação não confere com o que é } \\
\text { esperado. }\end{array}$ \\
\hline
\end{tabular}




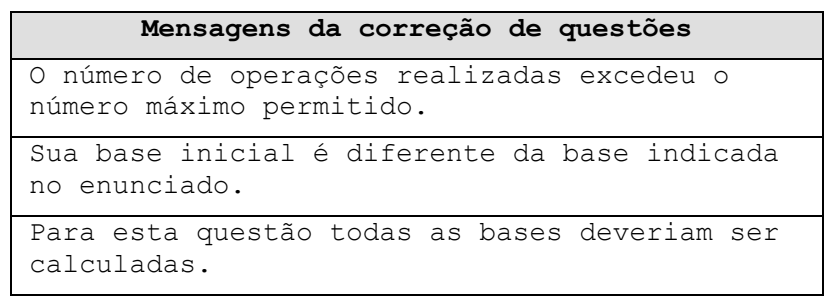

Fonte: Fonseca e Pinto, 2013.

Como a Calculadora LOpt é disponibilizada diretamente pela internet, ela contribui com o aprendizado individualmente. Dessa forma, o aluno pode utilizá-la quando desejar para, por exemplo, resolver questões, cadastradas anteriormente no banco de dados pelo professor, ou revisar problemas propostos em sala de aula.

\section{Estratégias de estudos da utilização do software no processo ensino e aprendizagem}

Esta seção é dedicada ao instrumento de pesquisa, à escolha do método estatístico e à técnica bootstrap, para tornar o trabalho de coleta e análise de dados viáveis para a utilização do software no processo de ensino e aprendizagem. Iniciamos o nosso propósito, apresentando o instrumento de pesquisa.

\subsection{Instrumento de pesquisa}

Foi utilizado como instrumento de pesquisa o questionário. A opção por esse instrumento se deve ao fato de que ele pode ser aplicado a um número grande de participantes sem que haja a necessidade de contato direto do pesquisador com o pesquisado e por ser um instrumento adequado à quantificação, devido à facilidade de codificação e tabulação, o que permite fazer comparações com outros dados relacionados ao tema pesquisado.

De acordo com Muñoz (2003), o questionário é considerado um instrumento clássico para a obtenção e registro de dados. Ele se constitui em uma técnica de avaliação que pode incluir aspectos quantitativos e qualitativos.

O questionário da presente pesquisa foi planejado e adaptado de Schreiner e Sjøberg (2004), Tolentino-Neto (2008) e Alvarenga e Sampaio (2013), com a finalidade de levantar as informações necessárias ao objetivo e à análise das hipóteses, totalizando 24 questões, sendo 23 questões fechadas, com alternativas pré-definidas e 1 questão aberta de forma a obter uma resposta pessoal e espontânea do participante (veja Anexo A). A Figura 4 apresenta as hipóteses abordadas no questionário de pesquisa.

A população amostrada constituiu-se de 81 participantes, sendo 54 alunos do curso de Engenharia Civil de uma instituição de ensino superior A, localizada em Anápolis e 27 alunos do curso de Administração de uma instituição de ensino superior B, localizada em Goiânia; ambas as cidades no centro-oeste do Brasil.

A aplicação do questionário impresso na instituição A foi realizada presencialmente pela professora pesquisadora na quinta aula sobre o método Simplex, quando da segunda oportunidade do uso da Calculadora LOpt. A aplicação na instituição B ocorreu sob circunstâncias parecidas com professor voluntário com uma única aula de laboratório. 


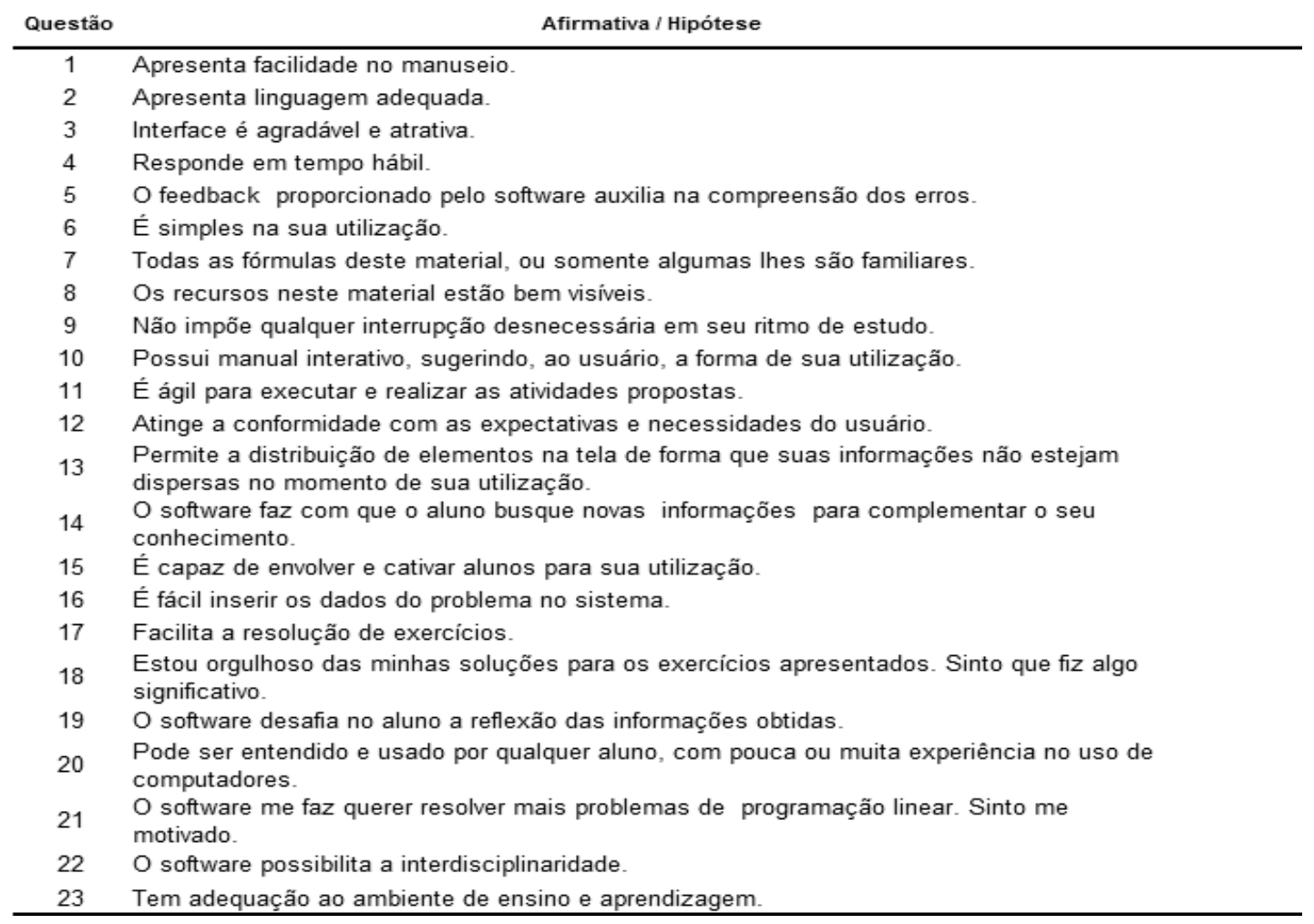

Figura 4: Hipóteses abordadas no questionário de pesquisa.

A escala utilizada no questionário é a escala Likert de quatro pontos, onde o respondente devia, para cada questão, indicar o grau de concordância ou discordância em relação às afirmações. A escala Likert é uma escala com um número ímpar de pontos e por isso ela possui um valor central "neutro", que pode ser uma desvantagem quando o respondente tem dúvida (Miguel, 2010). Já a escala Likert de quatro pontos obriga o participante a se posicionar e o aspecto ético sobre esta pressão é aliviado quando, na introdução do questionário, lhe é permitido deixar os itens sem respostas (Schreiner \& Sjøberg, 2004).

$\mathrm{Na}$ elaboração do questionário, procurou-se relacionar cada afirmação à hipótese do estudo. As afirmações referiam-se às questões de características de interface, de simplicidade, de qualidade e adaptabilidade do software no processo de ensino e aprendizagem.

\subsection{Escolha do método estatístico}

Como os questionários foram elaborados com base na escala Likert, os testes estatísticos paramétricos não são os métodos mais adequados, uma vez que a hipótese de normalidade na amostra é refutada. Portanto, optou-se por utilizar um método de reamostragem (bootstrap), cuja finalidade é garantir a normalidade entre as médias geradas pelo método e, consequentemente, gerar a possibilidade de aplicar testes de hipóteses paramétricos.

A seguir, será apresentada a técnica de reamostragem bootstrap que será utilizada nesta pesquisa. Nosso intuito é fazer estimativas de parâmetros da distribuição de interesse, a fim de obter propriedades de grandes amostras com base em um número reduzido de observações.

\subsection{Bootstrap}

O método bootstrap foi introduzido em 1979, por Efron, como uma técnica de reamostragem, usado principalmente na inferência estatística, quando, por exemplo, há interesse em estimar 
características da população, tais como média, variância, construção de intervalo de confiança, cálculos de valores-p, realização de testes de hipóteses, estimação de vícios etc. Conforme Efron (1979), o bootstrap é uma técnica estatística computacionalmente intensiva que permite a avaliação da variabilidade de estatísticas com base nos dados de uma amostra existente inicial.

A ideia básica desse método é tratar a amostra original como se esta fosse exatamente a população de interesse e dela retirar várias amostras com reposição, isto é, reamostrar a amostra original com reposição e, para cada reamostra, calcular a estimativa de interesse. O bootstrap pode ser implementado de duas maneiras, tanto de forma paramétrica quanto não paramétrica. Na primeira, desde que a distribuição dos dados seja conhecida, reamostram-se observações diretamente nessa distribuição e os parâmetros desconhecidos são substituídos por estimativas paramétricas. Na última, a reamostragem é feita na própria amostra, isto é, a amostra bootstrap é composta retirando uma amostra com reposição, de tamanho $n$, da amostra original.

O bootstrap não paramétrico pode ser usado para qualquer conjunto de dados, uma vez que ele não depende da distribuição que os dados seguem (distribuição desconhecida), o que permite sua maior aplicabilidade que o bootstrap paramétrico. Portanto, nesta pesquisa, utilizouse o método do bootstrap não paramétrico. A obtenção da amostra bootstrap, sua estimativa do erro padrão e o intervalo de confiança bootstrap foram calculados a partir dos seguintes passos, adaptados da definição dada por Efron (1979), cujo parâmetro $\theta$ a ser estimado é a média.

1. Dada uma amostra aleatória $\operatorname{de} f(x ; \hat{\theta}), x_{1}, x_{2}, x_{3} \ldots, x_{n}$ estime $\theta$, denotado por $\widehat{\theta}$.

2. Usando a estimativa $\widehat{\hat{\theta}}$, gere uma amostra de tamanho da distribuição $f(x ; \widehat{\theta})$. Essa é a amostra bootstrap.

3. Usando a amostra bootstrap, estime ${ }^{\theta}$. Denotando essa estimativa por $\widehat{\theta}_{\mathrm{i}}^{*}$.

4. Gere B amostras bootstrap para obter estimativas bootstrap, $\widehat{\theta}_{\mathrm{i}}^{*}$, para $\mathrm{i}=1,2, \ldots, \mathrm{B}$ $\mathrm{B}=100$ ou 200 é usado, em geral).

5. Represente por $\bar{\theta}^{*}=\sum_{\mathrm{i}=1}^{\mathrm{B}} \widehat{\theta}_{\mathrm{i}}^{*} / \mathrm{B}$ a média amostral das estimativas bootstrap.

6. O erro padrão bootstrap de $\bar{\theta}^{*}$ é encontrado com a fórmula usual do desvio-padrão (1),

$$
S_{\tilde{\theta}}=\sqrt{\frac{\sum_{i=1}^{B}\left(\hat{\theta}_{i}^{*}-\vec{\theta}^{*}\right)^{2}}{B-1}}
$$

O intervalo de confiança unilateral superior bootstrap t para uma determinada estatística foi calculado através de (2),

$$
\mathrm{IC}_{\text {bootstrap } \mathrm{t}}=\left\lfloor 0, \mu+\mathrm{t} . \mathrm{S}_{\widehat{\Theta}}\right\rfloor \text {, }
$$

sendo t encontrado utilizando $(n-1)$ graus de liberdade, considerando $n$ o tamanho da amostra original, denominada amostra mestre e $\mu$ parâmetro de aceitação.

O intervalo de confiança bootstrap t só funciona bem quando a estatística bootstrap tem um vício desprezível e quando a distribuição bootstrap for aproximadamente normal (Efron \& Tibshirani, 1986). Quando a distribuição amostral não estiver centrada no verdadeiro valor do parâmetro, considera-se que a estatística utilizada está viciada.

O estimador do vício da distribuição bootstrap, também denominado viés boot, é calculado fazendo a diferença entre a média da amostra bootstrap e a média da amostra mestre. Se a razão entre viés boot e o erro padrão boot, isto é, (viésboot $\left./ \mathrm{S}_{\widehat{\theta}}\right)<0,25$, pode-se dizer que ele está sob controle e, assim, desprezá-lo. 
Para este estudo foram realizadas 200 reamostragens, isto é, $B=200$, partindo da amostra mestre representada pelos 81 alunos que participaram da pesquisa, respondendo ao questionário. Quando as reamostragens são realizadas várias vezes, a estimativa numa amostra bootstrap se aproxima do valor real, sendo que o valor de B é escolhido de acordo com a finalidade para a qual o método bootstrap está sendo usado.

\subsubsection{Teste de hipóteses}

Muitas vezes, quando se retira uma amostra da população, não se sabe ao certo se alguma estatística dessa amostra corresponde realmente à população. Nessa situação, utilizam-se os testes de hipóteses para tomar decisões acerca da população, baseadas nas informações das amostras. Assim, o teste de hipótese é um processo em que se usam estatísticas amostrais para testar a afirmação sobre o valor de um parâmetro populacional e essa afirmação é chamada de hipótese estatística (Larson, 1982).

Para fazer uma afirmação sobre um parâmetro populacional, é necessário que se tenha um par de hipóteses: uma que represente a afirmação, chamada hipótese nula designada por $\mathrm{H}_{0}$, que é justamente uma afirmativa de que o resultado obtido em determinada pesquisa é igual ao resultado especificado, e a outra que represente o complemento dessa afirmação, chamada hipótese alternativa $\mathrm{H}_{1}$, que é justamente o resultado contrário de $\mathrm{H}_{0}$.

Uma vez que se conhece qual o $\mathrm{H}_{0}$ da análise a ser feita, é essencial realizar o teste sobre o par de hipóteses, de forma que a conclusão resultante irá rejeitar ou não a hipótese nula. Para tomar a decisão relacionada às hipóteses levantadas, é preciso selecionar o nível de significância $\alpha$, que expressa a probabilidade de rejeitar a hipótese nula (Larson, 1982).

Para todas as afirmativas do questionário, tomou-se como parâmetro de rejeição a média da população $(\mu)$ menor do que ou igual ao escore 3 , levando em consideração que a hipótese nula $\left(\mathrm{H}_{0}\right)$ é a de que o usuário do software não concorda com a afirmativa dada a cada pergunta do questionário. Sendo assim, construiu-se cada hipótese estatística, partindo da premissa de que a hipótese nula $\mathrm{H}_{0}$ é menor do que ou igual a 3 , que é a hipótese a ser refutada.

$\mathrm{H}_{0}: \mu \leq 3$ - Não concordam com a afirmação, ou seja, Não Rejeita $\mathrm{H}_{0}$;

$\mathrm{H}_{1}: \mu>3$ - Concordam com a afirmação, ou seja, Rejeita $\mathrm{H}_{0}$.

Nesta pesquisa, optou-se em trabalhar com o nível de significância determinando o P-valor ou $p$-value, relacionado ao valor observado da estatística de teste, adotando ${ }^{\alpha}=5 \%$, isto é, 0,05 . A regra de decisão foi:

1. $\mathrm{Se} \mathrm{p} \leq \alpha_{,}$então rejeita $\mathrm{H}_{0}$.

2. $\mathrm{Se} \mathrm{p}>\alpha_{p}$ então não rejeita $\mathrm{H}_{0}$.

Uma forma de estimar o valor-p empiricamente é pela equação (3), (3)

$\mathrm{p}=$ (número de médias bootstrap $\leq 3$ ) / número de reamostragens bootstrap.

Após a aplicação do questionário, os dados foram coletados e tabulados por meio do uso do aplicativo Microsoft Excel 2010. Esses dados se transformaram em importantes informações e propiciaram o processo de análise, de classificação, de realização dos testes de hipóteses e de interpretação dos resultados.

Dessa maneira, o tratamento estatístico teve caráter descritivo (amostragem, seleção, coleta, tabulação dos dados, descrição das observações coletadas) e indutivo (análise das 
observações, testes de associação, estimativa de proporções para a amostra estudada). A análise dos dados propriamente dita é realizada para testá-los e aferir a concordância com as hipóteses da investigação (Miguel, 2010).

\section{Apresentação e análise dos resultados}

Inicialmente, faremos uma análise descritiva e, posteriormente, faremos uma análise indutiva e uma análise qualitativa, respectivamente. Finalmente, discutiremos sobre as ameaças à validade, procedimento que é crucial em estudos empíricos.

\subsection{Análise descritiva}

A coleta de dados foi realizada a partir da aplicação do questionário de pesquisa, em que a primeira seção foi constituída de questões fechadas e dividida em quatro partes, objetivando avaliar os seguintes critérios: a característica da interface, a simplicidade, a qualidade e adaptabilidade do software. A segunda seção foi destinada a caracterizar a experiência do participante com o uso da calculadora, de modo que ele se expressasse através de 5 palavras, em uma única questão aberta.

\subsubsection{Avaliação da primeira seção}

Para avaliar a primeira seção do questionário, foi feita a média aritmética simples da pontuação obtida em cada afirmativa de cada critério. A Tabela 2 apresenta a média dessa pontuação do primeiro critério.

Tabela 2: Média dos pontos obtidos no $1^{\circ}$ critério.

\begin{tabular}{|l|l|}
\hline \multicolumn{1}{|c|}{ TECNOLOGIA } & \multicolumn{1}{c|}{ Média } \\
\hline (Caracteristicas da interface) & \\
\hline Facilidade no manuseio & 3,604938272 \\
\hline Linguagem adequada & 3,432098765 \\
\hline Interface agradável & 3,24691358 \\
\hline Responde em tempo hábil & 3,592592593 \\
\hline Feedback & 3,24691358 \\
\hline
\end{tabular}

No que se refere à tecnologia, as hipóteses "interface agradável" e "feedback" tiveram menores pontuações na avaliação, porém, essas foram satisfatórias, conforme ilustrado na Tabela 2.

Acredita-se que essa pontuação se deve ao fato de ser uma calculadora e não um software, por exemplo, de geometria dinâmica, em que o usuário tem a possibilidade de construir figuras geométricas e operar com elas. Já a hipótese que obteve maior pontuação foi a "facilidade no manuseio", pois, uma vez que o usuário tem um conhecimento prévio do conteúdo, basta que ele informe os dados na tela e a calculadora realiza as operações de acordo com o desejado.

A média da pontuação do segundo critério está representada na Tabela 3, a seguir. 
Tabela 3: Média dos pontos obtidos no $2^{\circ}$ critério.

\begin{tabular}{|l|l|}
\hline \multicolumn{1}{|c|}{ Simplicidade } & \multicolumn{1}{c|}{ Média } \\
\hline É simples na sua utilização & 3,641975309 \\
\hline Fórmulas familiares & 3,222222222 \\
\hline Recursos bem visíveis & 3,580246914 \\
\hline Não impõe qualquer interrupção & 3,567901235 \\
\hline
\end{tabular}

Nesse critério, os participantes consideraram que a utilização da calculadora é simples, como mostra a Tabela 3, em que essa hipótese se apresenta com maior pontuação. Em contrapartida, a hipótese de menor pontuação se refere às fórmulas descritas no software. Os participantes afirmaram que nem todas lhes eram familiares. Mesmo assim, todas as hipóteses tiveram pontuação média acima de 3 .

Com base na Tabela 4, nota-se que o terceiro critério, o qual trata da qualidade do software, também obteve uma pontuação conforme se esperava, isto é, acima de ou igual a 3.

Tabela 4: Média dos pontos obtidos no $3^{\circ}$ critério.

\begin{tabular}{|l|c|}
\hline \multicolumn{1}{|c|}{ Qualidade } & Média \\
\hline Possui manual interativo & 3,209876543 \\
\hline É ágil & 3,765432099 \\
\hline $\begin{array}{l}\text { Atinge a conformidade com as } \\
\text { expectativas }\end{array}$ & 3,641975309 \\
\hline Informações não ficam dispersas & 3,407407407 \\
\hline $\begin{array}{l}\text { Incentiva o aluno a buscar } \\
\text { novas informações }\end{array}$ & 3,074074074 \\
\hline
\end{tabular}

A hipótese de que a mediação pedagógica com o software "incentiva o aluno a buscar novas informações", se apresenta com menor valor, fato que se justifica porque se trata de uma calculadora com o objetivo específico de auxiliar nos cálculos de problemas de PL. Por outro lado, as hipóteses de que o software "atinge a conformidade com as expectativas e necessidades dos usuários" e é "ágil para executar e realizar as tarefas propostas" foram ressaltadas no resultado das avaliações, as quais alcançaram as maiores pontuações, como pode ser visto na Tabela 4.

O último critério avaliado, nessa seção, se refere a adaptabilidade do software no processo de ensino e aprendizagem. A Tabela 5 apresenta os resultados.

Tabela 5: Média dos pontos obtidos no $4^{\circ}$ critério.

\begin{tabular}{|l|c|}
\hline \multicolumn{1}{|c|}{ Adaptabilidade } & Média \\
\hline $\begin{array}{l}\text { É fácil inserir os dados do } \\
\text { problema }\end{array}$ & 3,75308642 \\
\hline $\begin{array}{l}\text { Facilita a resolução de } \\
\text { exercícios }\end{array}$ & 3,851851852 \\
\hline O aluno sente-se orgulhoso & 3,50617284 \\
\hline $\begin{array}{l}\text { Desafia no aluno a reflexão das } \\
\text { informações obtidas }\end{array}$ & 3,222222222 \\
\hline $\begin{array}{l}\text { Pode ser entendido e usado por } \\
\text { qualquer aluno }\end{array}$ & 3,320987654 \\
\hline $\begin{array}{l}\text { Faz querer resolver mais } \\
\text { problemas }\end{array}$ & 3,172839506 \\
\hline
\end{tabular}


Como foi dito anteriormente, as afirmativas no questionário de pesquisa em questão, sobretudo nesta última seção, foram formuladas com base na hipótese desta pesquisa, ou seja, de que o software servirá como apoio para os cálculos de problemas de PL, tornando esse processo mais fácil. Assim, esse resultado gera evidências de que o software facilitará a resolução dos exercícios, visto que a maior pontuação de todo questionário foi obtida por essa hipótese e, ainda, que ele terá adequação ao ambiente de ensino e aprendizagem, pois, como mostra a Tabela 5, estas hipóteses tiveram pontuação acima de 3,5.

\subsubsection{Avaliação da segunda seção}

A segunda seção se baseia nos resultados obtidos da questão dissertativa do questionário, em que o participante teve a liberdade de caracterizar sua experiência com a utilização da Calculadora LOpt, usando apenas cinco palavras. As caracterizações que surgiram, foram: ótimo, fácil, perfeito, simples, ágil, rápido, ajuda, prático, útil, dinâmico, aprendizagem, funcional, interativo, eficaz, facilitador, convidativo, pedagógico, entre outras.

A Figura 5 representa o percentual das cinco palavras mais citadas nessa seção. Foram elas: fácil, simples, ágil, rápido e prático. Portanto, observa-se que $30 \%$ das palavras mais citadas foi a palavra fácil. Isto indica que o software foi caracterizado como fácil 47 vezes. Como simples, 36 vezes, representado por $23 \%$ dessas palavras. Nota-se, também, que a palavra ágil foi citada 30 vezes, equivalendo a $19 \%$ do total. A palavra rápido apareceu 22 vezes, representando $14 \%$, e, por fim, a palavra prático que foi citada 21 vezes, ou seja, aproximadamente $14 \%$.

Vale ressaltar que nenhuma das inúmeras palavras que os participantes citaram, nessa seção, caracterizou a experiência como algo ruim. Pelo contrário, todas as palavras a caracterizaram como uma experiência boa.

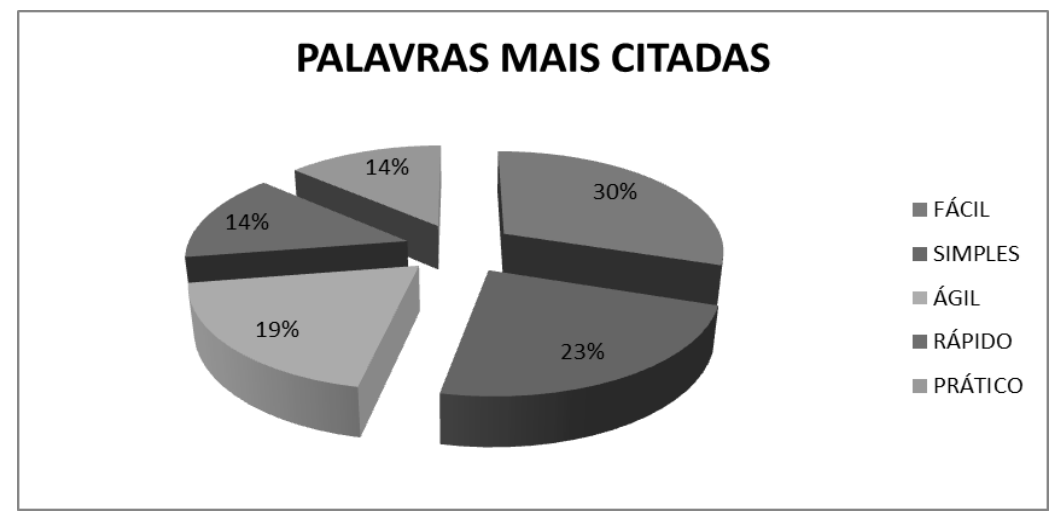

Figura 5: Gráfico das palavras mais citadas na questão dissertativa.

\subsection{Análise indutiva}

Após a tabulação dos dados, verificou-se que o conjunto amostral não representava uma distribuição normal, pois ele não tinha a média, a mediana e a moda com valores iguais e o gráfico da curva amostral era assimétrico, ou seja, não representava uma curva normal. Portanto, utilizou-se o método bootstrap não paramétrico, objetivando ajustar a amostra, tornando-a aproximadamente normal.

Para identificar o padrão do conjunto de dados, utilizou-se o gráfico de distribuição de frequências, o histograma. A Figura 6, apresenta o gráfico (antes dos dados serem ajustados) da última hipótese da pesquisa, a questão 23, a qual afirmava que o software tem adequação ao ambiente de ensino e aprendizagem. 


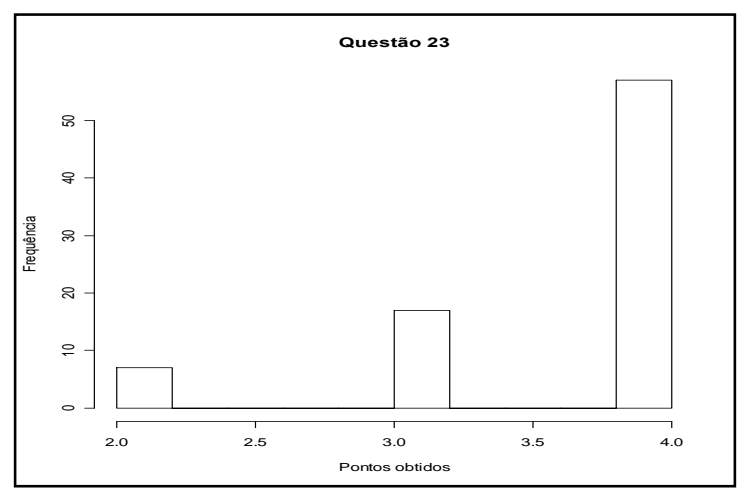

Figura 6: Histograma pontuação obtida na questão 23. Amostra mestre.

Nota-se realmente que a distribuição não é simétrica, logo, os dados dessa amostra mestre, não formam uma distribuição normal. Por outro lado, a Figura 7 apresenta o gráfico da mesma hipótese, após os dados serem ajustados.

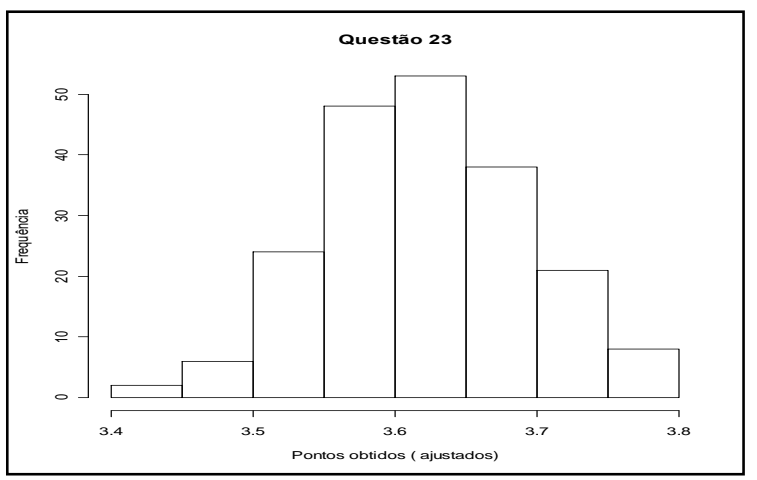

Figura 7: Histograma da pontuação obtida na questão 23. Amostra bootstrap

Observa-se que esse histograma assume a forma muito próxima à curva normal. Portanto, conclui-se que o método bootstrap se mostra adequado para este estudo, uma vez que os métodos tradicionais baseiam-se em suposições sobre distribuições para grandes amostras. $\mathrm{O}$ bootstrap é uma solução, caso a amostra seja pequena, pois ele gera uma distribuição empírica, fornecendo aproximações melhoradas para a distribuição, o que possibilita uma análise mais precisa, pois filtra as informações verdadeiramente relevantes nos resultados.

Observa-se que todas as afirmativas obtiveram média maior do que 3 dentro do intervalo de confiança obtido para cada afirmativa, logo, com 95\% de confiança, não se pode rejeitar a hipótese $\mathrm{H}_{0}$. Isto indica que os participantes avaliam que a utilização do software dará grandes contribuições ao estudo e à resolução de problemas de PL. Ao aplicar o bootstrap, verificou-se que o viés se manteve sob o controle, isto é, viés boot $<0,25$. $_{\widehat{\Theta}}$, garantindo, assim, que a estatística de teste bootstrap não está viciada, portanto, ele foi desprezado.

O cálculo do viés encontra-se descrito na Tabela 6 a seguir. 
Tabela 6: Cálculo das estatísticas usando o método bootstrap.

\begin{tabular}{|c|c|c|c|c|c|c|}
\hline Questão & Afirmativa & $\begin{array}{l}\text { Média da } \\
\text { Amostra }\end{array}$ & $\begin{array}{l}\text { Média } \\
\text { BOOTS }\end{array}$ & $\begin{array}{l}\text { Erro } \\
\text { BOOT }\end{array}$ & Viés ${ }_{B O O T}$ & $\begin{array}{l}\text { Viés sob } \\
\text { Controle } \\
(<0,25)\end{array}$ \\
\hline 1 & $\begin{array}{l}\text { Apresenta facilidade no } \\
\text { manuseio. }\end{array}$ & 3,604938 & 3,605679 & 0,069574 & 0,000741 & 0,010646804 \\
\hline 2 & Apresenta linguagem adequada. & 3,432099 & 3,425309 & 0,0863 & $-0,00679$ & 0,078680435 \\
\hline 3 & $\begin{array}{l}\text { Interface é agradável e } \\
\text { atrativa. }\end{array}$ & 3,246914 & 3,243333 & 0,082896 & $-0,00358$ & 0,043189672 \\
\hline 4 & Responde em tempo hábil. & 3,592593 & 3,595494 & 0,07665 & 0,002901 & 0,03785022 \\
\hline 5 & $\begin{array}{l}\text { O feedback proporcionado pelo } \\
\text { software auxilia na } \\
\text { compreensão dos erros. }\end{array}$ & 3,246914 & 3,248272 & 0,083751 & 0,001358 & 0,016215073 \\
\hline 6 & É simples na sua utilização. & 3,641975 & 3,643519 & 0,070487 & 0,001543 & 0,02189347 \\
\hline 7 & $\begin{array}{l}\text { Todas as fórmulas deste } \\
\text { material, ou somente algumas } \\
\text { lhes são familiares. }\end{array}$ & 3,222222 & 3,225679 & 0,081545 & 0,003457 & 0,042391099 \\
\hline 8 & $\begin{array}{l}\text { Os recursos neste material } \\
\text { estão bem visíveis. }\end{array}$ & 3,580247 & 3,575864 & 0,06724 & $-0,00438$ & 0,065180622 \\
\hline 9 & $\begin{array}{l}\text { Não impõe qualquer interrupção } \\
\text { desnecessária em seu ritmo de } \\
\text { estudo. }\end{array}$ & 3,567901 & 3,573395 & 0,078154 & 0,005494 & 0,070294477 \\
\hline 10 & $\begin{array}{l}\text { Possui manual interativo, } \\
\text { sugerindo, ao usuário, a forma } \\
\text { de sua utilização. }\end{array}$ & 3,209877 & 3,206173 & 0,081395 & $-0,0037$ & 0,045502969 \\
\hline 11 & $\begin{array}{l}\text { É ágil para executar e } \\
\text { realizar as atividades } \\
\text { propostas. }\end{array}$ & 3,765432 & 3,762099 & 0,057321 & $-0,00333$ & 0,058151598 \\
\hline 12 & $\begin{array}{l}\text { Atinge a conformidade com as } \\
\text { expectativas e necessidades do } \\
\text { usuário. }\end{array}$ & 3,641975 & 3,639877 & 0,063182 & $-0,0021$ & 0,033217983 \\
\hline 13 & $\begin{array}{l}\text { Permite a distribuição de } \\
\text { elementos na tela de forma que } \\
\text { suas informações não estejam } \\
\text { dispersas no momento de sua } \\
\text { utilização. }\end{array}$ & 3,407407 & 3,409444 & 0,075675 & 0,002037 & 0,026918248 \\
\hline 14 & $\begin{array}{l}\text { O software faz com que o aluno } \\
\text { busque novas informações para } \\
\text { complementar o seu } \\
\text { conhecimento. }\end{array}$ & 3,074074 & 3,07142 & 0,085368 & $-0,00265$ & 0,031092855 \\
\hline 15 & $\begin{array}{l}\text { É capaz de envolver e cativar } \\
\text { alunos para sua utilização. }\end{array}$ & 3,345679 & 3,343395 & 0,07681 & $-0,00228$ & 0,029735026 \\
\hline 16 & $\begin{array}{l}\text { É fácil inserir os dados do } \\
\text { problema no sistema. }\end{array}$ & 3,753086 & 3,752099 & 0,062167 & $-0,00099$ & 0,015887037 \\
\hline 17 & $\begin{array}{l}\text { Facilita a resolução de } \\
\text { exercícios. }\end{array}$ & 3,851852 & 3,85679 & 0,048459 & 0,004938 & 0,101906164 \\
\hline 18 & $\begin{array}{l}\text { Estou orgulhoso das minhas } \\
\text { soluções para os exercícios } \\
\text { apresentados. Sinto que fiz } \\
\text { algo significativo. }\end{array}$ & 3,506173 & 3,50679 & 0,064572 & 0,000617 & 0,009559551 \\
\hline 19 & $\begin{array}{l}\text { O software desafia no aluno a } \\
\text { reflexão das informações } \\
\text { obtidas. }\end{array}$ & 3,222222 & 3,223395 & 0,087757 & 0,001173 & 0,013364697 \\
\hline 20 & $\begin{array}{l}\text { Pode ser entendido e usado por } \\
\text { qualquer aluno, com pouca ou } \\
\text { muita experiência no uso de } \\
\text { computadores. }\end{array}$ & 3,320988 & 3,317407 & 0,09363 & $-0,00358$ & 0,03823822 \\
\hline 21 & $\begin{array}{l}\text { O software me faz querer } \\
\text { resolver mais problemas de } \\
\text { programação linear. Sinto me } \\
\text { motivado. }\end{array}$ & 3,17284 & 3,167716 & 0,09329 & $-0,00512$ & 0,054919697 \\
\hline 22 & $\begin{array}{l}\text { O software possibilita a } \\
\text { interdisciplinaridade. }\end{array}$ & 3,17284 & 3,164136 & 0,090692 & $-0,0087$ & 0,095969611 \\
\hline 23 & $\begin{array}{l}\text { Tem adequação ao ambiente de } \\
\text { ensino e aprendizagem. }\end{array}$ & 3,617284 & 3,619012 & 0,069849 & 0,001728 & 0,024744852 \\
\hline
\end{tabular}


A Tabela 7 mostra o resultado obtido, através do teste de hipótese aplicado, relacionado ao valor da estatística de teste e seus respectivos limites superiores dos intervalos de confiança.

Tabela 7: Resumo do método bootstrap, para o cálculo do valor P.

\begin{tabular}{|c|c|c|c|c|c|}
\hline Questão & Afirmativa/Hipótese & Média BOOTS & $\begin{array}{l}\text { Limite } \\
\text { Superior } \\
\text { (LS) }\end{array}$ & $\begin{array}{l}\text { P-valor } \\
(\mathrm{P}>0,05)\end{array}$ & $\begin{array}{l}\text { Hipótese } \\
\text { nula (HO) }\end{array}$ \\
\hline 1 & Apresenta facilidade no manuseio. & 3,605679012 & 3,1157781 & 0 & Rejeita HO \\
\hline 2 & Apresenta linguagem adequada. & 3,425308642 & 3,14361187 & 0 & Rejeita HO \\
\hline 3 & Interface é agradável e atrativa. & 3,243333333 & 3,13794707 & 0 & Rejeita HO \\
\hline 4 & Responde em tempo hábil. & 3,595493827 & 3,12755393 & 0 & Rejeita HO \\
\hline 5 & $\begin{array}{l}\text { O feedback proporcionado pelo } \\
\text { software auxilia na compreensão dos } \\
\text { erros. }\end{array}$ & 3,248271605 & 3,13936964 & 0,005 & Rejeita HO \\
\hline 6 & É simples na sua utilização. & 3,643518519 & 3,11729779 & 0 & Rejeita HO \\
\hline 7 & $\begin{array}{l}\text { Todas as fórmulas deste material, ou } \\
\text { somente algumas lhes são familiares. }\end{array}$ & 3,225679012 & 3,13569935 & 0 & Rejeita $\mathrm{HO}$ \\
\hline 8 & $\begin{array}{l}\text { Os recursos neste material estão bem } \\
\text { visíveis. }\end{array}$ & 3,575864198 & 3,11189334 & 0 & Rejeita HO \\
\hline 9 & $\begin{array}{l}\text { Não impõe qualquer interrupção } \\
\text { desnecessária em seu ritmo de } \\
\text { estudo. }\end{array}$ & 3,573395062 & 3,13005684 & 0 & Rejeita HO \\
\hline 10 & $\begin{array}{l}\text { Possui manual interativo, sugerindo, } \\
\text { ao usuário, a forma de sua } \\
\text { utilização. }\end{array}$ & 3,20617284 & 3,13544904 & 0,01 & Rejeita HO \\
\hline 11 & $\begin{array}{l}\text { É ágil para executar e realizar as } \\
\text { atividades propostas. }\end{array}$ & 3,762098765 & 3,09538861 & 0 & Rejeita HO \\
\hline 12 & $\begin{array}{l}\text { Atinge a conformidade com as } \\
\text { expectativas e necessidades do } \\
\text { usuário. }\end{array}$ & 3,639876543 & 3,10514051 & 0 & Rejeita $\mathrm{HO}$ \\
\hline 13 & $\begin{array}{l}\text { Permite a distribuição de elementos } \\
\text { na tela de forma que suas } \\
\text { informações não estejam dispersas no } \\
\text { momento de sua utilização. }\end{array}$ & 3,409444444 & 3,12593068 & 0 & Rejeita HO \\
\hline 14 & $\begin{array}{l}\text { O software faz com que o aluno } \\
\text { busque novas informações para } \\
\text { complementar o seu conhecimento. }\end{array}$ & 3,071419753 & 3,14206015 & 0,23 & $\begin{array}{c}\text { Não Rejeita } \\
\text { HO }\end{array}$ \\
\hline 15 & $\begin{array}{l}\text { É capaz de envolver e cativar alunos } \\
\text { para sua utilização. }\end{array}$ & 3,343395062 & 3,12781971 & 0 & Rejeita HO \\
\hline 16 & $\begin{array}{l}\text { É fácil inserir os dados do problema } \\
\text { no sistema. }\end{array}$ & 3,752098765 & 3,10345262 & 0 & Rejeita $\mathrm{HO}$ \\
\hline 17 & Facilita a resolução de exercícios. & 3,856790123 & 3,08064063 & 0 & Rejeita HO \\
\hline 18 & $\begin{array}{l}\text { Estou orgulhoso das minhas soluções } \\
\text { para os exercícios apresentados. } \\
\text { Sinto que fiz algo significativo. }\end{array}$ & 3,506790123 & 3,10745507 & 0 & Rejeita $\mathrm{HO}$ \\
\hline 19 & $\begin{array}{l}\text { O software desafia no aluno a } \\
\text { reflexão das informações obtidas. }\end{array}$ & 3,223395062 & 3,14603565 & 0,005 & Rejeita H0 \\
\hline 20 & $\begin{array}{l}\text { Pode ser entendido e usado por } \\
\text { qualquer aluno, com pouca ou muita } \\
\text { experiência no uso de computadores. }\end{array}$ & 3,317407407 & 3,15580979 & 0 & Rejeita HO \\
\hline 21 & $\begin{array}{l}\text { O software me faz querer resolver } \\
\text { mais problemas de programação } \\
\text { linear. Sinto me motivado. }\end{array}$ & 3,167716049 & 3,15524384 & 0,045 & Rejeita HO \\
\hline 22 & $\begin{array}{l}\text { O software possibilita a } \\
\text { interdisciplinaridade. }\end{array}$ & 3,164135802 & 3,15092104 & 0,03 & Rejeita HO \\
\hline 23 & $\begin{array}{l}\text { Tem adequação ao ambiente de ensino } \\
\text { e aprendizagem. }\end{array}$ & 3,619012346 & 3,11623518 & 0 & Rejeita HO \\
\hline
\end{tabular}


Como apresentado na Tabela 7 , nota-se que, com exceção da questão 14 , todas as afirmativas tiveram o P-valor maiores do que 0,05 . Então, de acordo com a regra de decisão, se pode rejeitar $\mathrm{H}_{0}$ e, consequentemente, se aceita a hipótese alternativa; portanto, mais uma vez, conclui-se que há evidências de que o software, quando utilizado como uma ferramenta de apoio para o estudo de problemas de PL, facilitará o processo de resolução dos cálculos. Isso porque ele é simples de manusear, fácil de inserir os dados, envolve e cativa os usuários para a sua utilização, gera resultados rápidos, enfim, atende às expectativas e necessidades do usuário. Desse modo, verifica-se que os usuários podem se beneficiar com o uso desta nova ferramenta. Quanto à questão de número 14, "o software faz com que o aluno busque novas informações para complementar o seu conhecimento", ela foi a única que não teve a hipótese nula rejeitada, fato que se justifica por a calculadora ter o objetivo específico de auxiliar nos cálculos de problemas de PL, conforme justificado quando da Tabela 4, mas, também, indicando que a Calculadora LOpt deve melhorar nesse aspecto.

\subsection{Análise qualitativa}

Por meio de uma observação direta, realizada pelos professores, ficou evidente que, ao receberem a proposta de utilização do software, os alunos demonstraram reação positiva, ficaram eufóricos e entusiasmados, pois inicialmente, acreditavam que o software poderia ser um meio facilitador durante o processo de resolução de exercícios Ainda nesse momento, ressaltaram que a utilização por parte do professor poderia ser um auxílio a mais na percepção das dificuldades de cada aluno. Há indícios nesse sentido, conforme se constata nas palavras dos próprios alunos, como as elencadas a seguir:

- Acredito que a utilização do software pode ser um meio para o professor perceber a dificuldade dos alunos, assim, fazer uma revisão de conteúdo.

- É algo inusitado!

De maneira geral, as turmas acharam que o software é fácil de ser manuseado, isto é, simples para a inserção de dados e apresenta os resultados para as questões propostas de forma clara, cria um ambiente de aprendizagem satisfatório, o que é importante quando se trata do tempo despendido na resolução de cada exercício. Neste caso, nos respaldamos nas manifestações comportamentais dos alunos com demonstrações de satisfação, conforme alguns registros verbalizados:

- Nossa, tá tudo aqui! Até o dual!

- O cálculo manual facilita a fixação do método, porém, se torna mais trabalhoso e devido à quantidade de cálculos a atenção deve ser redobrada, ao contrário de quando foi utilizado o software.

Os participantes também comentaram sobre a flexibilidade do sistema, por exemplo:

- Posso errar e voltar para consertar. É gratificante receber o feedback que o sistema oferece por meio das mensagens de correção e no esforço em cada interação usuário/máquina, que é muito pequeno.

Porém, houve dificuldades na etapa dos cálculos, sobretudo nas turmas de Pesquisa Operacional, o que provocou uma discussão acerca desse fato:

- Por que que cada botão não poderia ter uma nomenclatura?

Foi argumentado que a ideia do software é facilitar o trabalho do usuário no momento em que for desenvolver os cálculos e que ele pressupõe o conhecimento do conteúdo para resolver um problema de PL. Essas informações já haviam sido apresentadas quando realizou-se 
o estudo do método Simplex em sala de aula. Nesse contexto, após o trabalho com a Calculadora LOpt, alguns alunos se manifestaram. Seguem-se alguns registros:

- Resolver o problema através do software facilitou os cálculos, pois as etapas ficaram bastante intuitivas.

- Apresenta o passo a passo da resolução.

A escolha destas turmas foi influenciada pelo fato de todos serem ou estarem trabalhando com PL. A aplicação do software ocorreu em aulas realizadas pelos professores das disciplinas nos laboratórios de informática, onde todos os alunos tiveram acesso a um computador individual para resolver uma lista de exercícios proposta. Vale destacar que, durante essa experiência, houve interferência mínima por parte dos professores. Na próxima subseção trataremos sobre ameaças à validade do experimento.

\subsection{Avaliação da validade}

Uma questão fundamental concernente aos resultados de um experimento é quão válido eles são. Dessa forma, é importante questionar a validade dos resultados. Trataremos deste tema baseados em Wohlin et al (2012).

Segundo Cook e Campbell (1979), a validade pode ser dividida em quatro classes principais: validade interna, validade externa, validade de construto e validade de conclusão. Os autores também apresentam uma tabela de ameaças para cada classe de validade, assim como prioridades entre tipos de ameaças à validade em pesquisa aplicada.

A seguir, vamos apresentar cada classe de validade, ameaças à validade e discutir ameaças à validade específicas neste trabalho (denominado experimento, nesta subseção).

\subsubsection{Validade interna}

A validade interna está relacionada à validade dentro do ambiente dado e à confiabilidade dos resultados. Ameaças à validade interna referem-se às questões que podem indicar uma relação causal, embora não haja nenhuma.

Existem duas ameaças à validade interna significativas neste experimento: a seleção e a instrumentação. Após utilizarmos a Calculadora LOpt em uma turma de nove alunos do penúltimo semestre dos cursos de Ciência da Computação e Engenharia de Computação, pensamos em selecionar turmas de outros cursos porque observamos a facilidade dos alunos com o software. Assim, uma das pesquisadoras tomou uma turma de Engenharia Civil em outra instituição (instituição A), no semestre seguinte, e um professor voluntário tomou uma turma de Administração na instituição de origem B. Acreditamos que esta seleção não aleatória amenizou o viés do pesquisador, o qual tem expectativa em obter resultados positivos. Além disso, a instrumentação neste experimento é caracterizada pelo questionário. O uso exclusivo de assertivas positivas na aplicação do questionário pode induzir o participante que responde a marcar de forma positiva todas as questões. Todavia, antes da aplicação do questionário, tivemos discussões sobre o software, em que as turmas questionaram, por exemplo,

"Por que os botões não estão em ordem com o procedimento do algoritmo simplex? Sem essa mistura ficaria mais fácil e mais rápido!"

Não podemos afirmar se com a discussão desta questão/sugestão, por exemplo, induzimos o participante a marcar, no dia da aplicação do questionário, por exemplo, "CONCORDE PARCIALMENTE" ao invés de "DISCORDE PARCIALMENTE" (veja Anexo A). Além disso, a questão 24 é uma questão aberta. 


\subsubsection{Validade externa}

A validade externa é uma questão que analisa o quão gerais são os resultados encontrados. Ameaças à validade externa dizem respeito à capacidade de generalizar os resultados encontrados fora da configuração do experimento.

A validade externa, neste experimento, provavelmente não é um problema, haja vista que o software é proposto principalmente para alunos de disciplinas que abordam o algoritmo Simplex e o experimento foi realizado nestas condições.

\subsubsection{Validade de construto}

A validade de construto está ligada à relação entre teoria e observação. Ameaças à validade de construto referem-se à medida que a configuração do experimento realmente reflete a construção sob estudo. A validade de construto, neste experimento, provavelmente não é um problema também, uma vez que os alunos apenas contribuíram com o experimento.

\subsubsection{Validade de conclusão}

Um experimento estuda o efeito de mudanças de uma ou mais variáveis independentes, isto é, variáveis em um processo que são manipuladas e controladas e às quais são chamadas de fatores. Chamamos de tratamento (treatment) a um valor particular de um fator. A validade de conclusão está ligada à relação entre o tratamento e o resultado. Ameaças à validade de conclusão referem-se às questões que afetam a capacidade de tirar a conclusão correta sobre as relações entre o tratamento e o resultado.

Existem duas ameaças à validade de conclusão significativa neste experimento: a confiabilidade da implementação do tratamento e a heterogeneidade aleatória do sujeito. Considerando o tratamento como a aplicação do questionário, a pesquisadora na instituição A ministrou cinco aulas sobre o método Simplex e duas aulas de laboratório com a utilização da Calculadora LOpt, antes de aplicar o questionário. Já na instituição B, o professor voluntário teve uma aula de laboratório a menos antes da aplicação do questionário. Acreditamos que uma aula de laboratório com a utilização da Calculadora LOpt fornece um diferencial, mas não chegamos a monitorar cada aluno quanto à utilização do software online, o que poderia minimizar o viés da aplicação. Além disso, considerando os alunos como sujeitos, a diferença entre cursos de graduação em instituições particulares de uma mesma região do Brasil ameniza o viés da heterogeneidade. Na próxima seção, serão apresentadas as considerações finais do trabalho.

\section{Considerações finais}

Este trabalho teve como objetivo avaliar as contribuições que o software denominado Calculadora LOpt pode oferecer quando inserido como uma ferramenta de apoio ao ensino para a resolução de problemas de PL por meio do algoritmo Simplex. A construção de um questionário que avalia ferramentas tecnológicas em sala de aula e, em particular, a Calculadora LOpt, foi o nosso primeiro resultado.

Em seguida, ao fazer uso do método bootstrap, verificou-se que há evidências de que o software, quando utilizado como instrumento de apoio ao ensino na resolução de problemas de PL, contribuirá de forma considerável para o aprendizado do aluno, no que diz respeito à obtenção dos resultados dos exercícios de forma rápida, no esforço dedicado em cada etapa de cada exercício proposto, na flexibilidade do sistema, no feedback que ele oferece. Além disso, ele propicia ao aluno refletir sobre as informações obtidas e pode ser entendido e usado por 
qualquer aluno, com pouca ou muita experiência no uso de computadores, na criação de um ambiente de aprendizagem altamente interativo, melhorando, assim, a qualidade de ensino em sala de aula. Considera-se este o nosso segundo resultado.

Em 2015, a Calculadora LOpt se profissionalizou com outro nome. Atualmente, em 2017, ela está em sua segunda versão. Todavia, espera-se que com este trabalho se possa contribuir para reforçar a necessidade das tecnologias informáticas serem incorporadas às práticas docentes na área de pesquisa operacional. E, ainda, acredita-se que os cursos de graduação e pós-graduação, que possuem disciplinas de pesquisa operacional ou PL, que adotarem essa tecnologia como um instrumento de apoio ao ensino terão um ganho quando comparados com outros cursos que continuarem resolvendo problemas dessa natureza somente de forma manual ou com tecnologias, às vezes, incompatíveis.

Como trabalhos futuros, pode-se observar que com este trabalho demos um passo anterior à aplicação do software. Desta forma, poderemos avaliar turmas através da utilização da nova versão da Calculadora LOpt. Além disso, poderemos avaliar outros softwares específicos para otimização com a utilização do questionário e do método bootstrap, conforme utilizamos aqui.

\section{Agradecimentos}

Gostaríamos de agradecer ao colega Leizer de Lima Pinto pela colaboração em vários momentos deste trabalho. E, também, a um dos revisores deste artigo pelas várias sugestões e correções que contribuíram para a melhoria deste trabalho.

\section{Referências}

Alencar, W. de S., Rocha, B. M., Nogueira, E. A., Fernandes, R. F., \& Nunes, F. A. A. de M. (2012). RHODES 2.0: Software Educacional para o Ensino de Programação Linear. In Anais do XXIII Simpósio Brasileiro de Informática na Educação (SBIE).Disponível em: http://br-ie.org/pub/index.php/sbie/article/view/1769. [GS Search]

Alvarenga, K. B., \& Sampaio, M. M. (2013). Um perfil de estudantes do ensino médio frente à matemática: o caso de um colégio da cidade de Itabaiana - Sergipe. In Anais do VII Colóquio Internacional "Educação e Contemporaneidade”, São Cristovão/ Sergipe. [GS Search]

Alves, A. C. B., \& Menezes, M. A. F. (2010). Introdução à pesquisa operacional. Goiânia: Editora da PUC Goiás.

Beale, E. M. L. (1955). Cycling in the dual simplex algorithm. Naval Research Logistics Quarterly, 2, 269-275. doi: 10.1002/nav.3800020406 [GS Search]

Cook, T. D., \& Campbell, D. T. (1979). Quasi-experimentation in - Design and Analysis Issues for Field Settings. Boston: Houghton Mifflin Company.

Dantzig, G. B. (1951). Maximization of a linear function of variables subject to linear inequalities. In T. C. Koopmans (Ed.). Activity Analysis of Production and Allocation (pp.339-347). NY: John Wiley. [GS Search]

Efron, B. (1979). Bootstrap methods: another look at the jacknife. The Annals of Statistics, 7, 126. doi: 10.1007/978-1-4612-4380-9_41 [GS Search] 
Efron, B., \& Tibshirani, R. (1986). Bootstrap methods for standard errors, confidence intervals, and other measures of statistical accuracy (with discussion). Statistical Science, 1, 54. [GS Search]

Fonseca, F. F., \& Pinto, L. L. (2013). Uma ferramenta de apoio para professores e estudantes em cursos de Pesquisa Operacional. In Anais do XLV Simpósio Brasileiro de Pesquisa Operacional, Natal/RN, 824-831. Disponível em: http:/www.din.uem.br/ ademir/sbpo/sbpo2013/pdf/arq0391.pdf [GS Search]

Gondzio, J., \& Grothey, A. (2006). Direct solution of linear systems of size $10^{9}$ arizing in optimization with interior point methods. In R. Wyrzykowski, J. Dongarra, N. Meyer \& J. Wasniewski (eds.). Parallel Processing and Applied Mathematics PPAM 2005, (pp.513525) Lecture Notes in Computer Science, 3911, Berlim: Springer-Verlag. doi: $\underline{10.1007 / 11752578 \_62}$ [GS Search]

Griffith, L. K. (1998). Impact of technology on pedagogy. In E. D. Laughbaum (Ed.). Hand-held technology in mathematics and science education: a collection of papers. (pp. 76-77). Columbus, $\mathrm{OH}$ : The Ohio State University.

Klee, V., \& Minty, G. J. (1972). How Good is the Simplex Algorithm? In O. Shisha (ed.). Inequalities III, (159-175). Academic Press. [GS Search]

Kydd, C. T. (2012). The Effectiveness of Using a Web-Based Applet To Teach Concepts of Linear Programming: An Experiment in Active Learning. INFORMS Transactions on Education, 12(2), 67-77. doi: 10.1287/ited.1110.0076 [GS Search]

Larson, H. J. (1982). Introduction to Probability Theory and Statistical Inference. $3^{\text {rd }}$ ed, New York: John Wiley \& Sons. [GS Search]

Lazaridis, V., Paparrizos, K., Samaras, N., \& Sifaleras, A. (2007). Visual LinProg: A webbased educational software for linear programming. Computer Applications in Engineering Education, 15(1), 1-14. doi: 10.1002/cae.20084 [GS Search]

Mateo, J., Borrell, K., Pla, L., \& Solsona, A. F. (2017). Pàges-Bernaus. Deterministic linear optimization as a service. In Anais da XXI Conferência da IFORS, Quebec City/CA, Technical Program, 133.

Miguel, P. A. C. (2010). Metodologia de pesquisa em engenharia de produção e gestão de operações. Rio de Janeiro: Elsevier.

Muñoz , T. G. (2003, Marzo). El cuestionario como instrumento de investigación/evaluación. Almendralejo. Acessado em $\quad$ Set. 2017 em: http://www.univsantana.com/sociologia/El_Cuestionario.pdf [GS Search]

Pinto, L. L., \& Bornstein, C. T. (2006). Um software interativo para o algoritmo simplex em programação linear. In Anais do XXXVIII Simpósio Brasileiro de Pesquisa Operacional, Goiânia/GO, 421-431. [GS Search]

Posada, J. E. G., Buchdid, S. B., \& Baranauskas, M. C. (2016). A informática na educação: o que revelam os trabalhos publicados no Brasil. Revista Brasileira de Informática na Educação, 24(1), 141-155. doi: 10.5753/rbie.2016.24.1.142 [GS Search]

Schreiner, C., \& Sjøberg, S. (2004). Sowing the Seeds of ROSE. The Relevance of science education. Acta Didactica, 4. Acessado em Set. 2017, em: https://roseproject.no/keydocuments/key-docs/ad0404-sowing-rose.pdf ISSN: 1502-2013 ISBN: 82-90904-79-7 
Tan, C. K. (2012). Effects of the application of graphing calculator on students' probability achievement. Computers \& Education, 58, 1117-1126. doi: $10.1016 /$ j.compedu.2011.11.023 [GS Search]

Tolentino-Neto, L. C. B. (2008). Os interesses e posturas de jovens alunos frente às ciências: resultados do Projeto ROSE no Brasil. Tese de doutorado, Faculdade de Educação, Universidade de São Paulo. Acessado em: Set. 2017 em: http://roseproject.no/network/countries/brazil/bra-caldeira-tolentino-neto.pdf. $\quad$ doi: 10.11606/T.48.2008.tde-16062008-155323 [GS Search]

Wohlin, C., Runeson, P., Höst, M., Ohlsson, M. C. , Regnell, B., \& Wesslén, A. (2012). Experimentation in Software Engineering. Berlin: Springer. doi: 10.1007/978-1-4615-4625$\underline{2}$ [GS Search]

Zamora, L. P., \& Torres, A. (2017). Comics as a tool for teaching and learning OR. In Anais da XXI Conferência da IFORS, Quebec City/CA, Technical Program, 75. 